\title{
Title: The ELALC-SEK Project: Developing English language library classrooms to support literacy learning in the early childhood and primary English language programs at a multilingual Spanish school.
}

\author{
Cynthia R. Houston \\ Assistant Professor \\ Western Kentucky University \\ United States
}

\begin{abstract}
Two consultants from Western Kentucky University developed a proposal for and then assisted with the implementation of English Language Arts Library Classrooms in a private Spanish school near Barcelona, Spain. The intent of the project was to enhance the English instruction in the primary grades program at the school. The project involved field observations and a literature review of school libraries in Spain, proposal development, technical assistance, and training in library organization, administration and collection development.
\end{abstract}

literacy and language acquisition, school libraries, English as a foreign language instruction

\section{Introduction}

As part of their natural development, children in the early primary grades are acquiring language in all its forms and eagerly engaged in developing their listening, speaking, reading and writing skills. In countries where multiple languages are spoken, this language acquisition process takes on added dimensions, as children learn to distinguish and use their different languages in daily communication. For two school library consultants from Western Kentucky University in Bowling Green, observing the language acquisition process of young children in a multi-lingual Spanish school was a profound experience, one which has forever changed our approach to serving the literacy needs of our own linguistically diverse communities.

The project that brought us to the SEK (San Estanislao de Kostka) Catalunya, a private P-12 school near Barcelona is called the ELALC-SEK. or the English Language Arts Library Classroom project. Over a four year period, I, along with my colleague, Roxanne Spencer, consulted on the development of library classroom-based language arts programs and resources for the SEK's early childhood and primary (P-5) English programs. During this process we engaged in a literature review, field observations, interviews with teachers, proposal development, program implementation, collection development, and professional development activities for teachers at the SEK. This paper will describe the different elements of the ELALC-SEK project and the impact of each of these activities has had on those involved. 


\section{The SEK Catalunya (http://www.sek.es/schools/sek-catalunya/)}

The SEK Catalunya campus is one of eight P-12 schools in the SEK system. The SEK Catalunya markets itself as a progressive school, dedicated to developing the whole child though project addresses developmental and interests. The the International program at the and very recently version of this recognized degree Years or PYP committed for a global

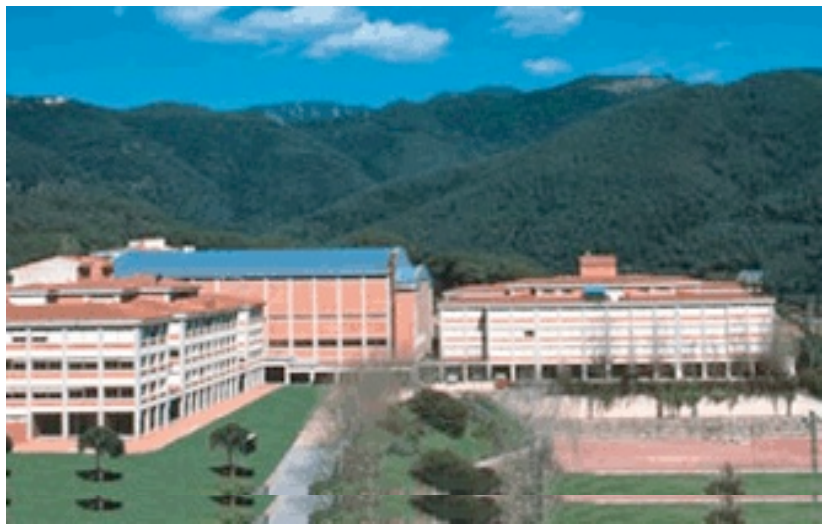
development of multiple languages. based learning that students' phase, learning needs SEK-Catalunya offers Baccalaureate secondary (6-12) level has begun the primary internationally

called the Primary program. The SEK is developing students society and fosters the literacy skills in In this school, instruction is provided in three languages, Catalan, Spanish, and English, with additional classes in other languages available at the secondary level. At the primary level the day is divided fairly equally between English, Catalan and Spanish, with different teachers dedicated to providing content area instruction in each of these languages. For the most part, instruction at the primary level in English covers the language arts, including reading, writing, and literature-based activities. Other subject areas such as science and social studies are taught in either Spanish or Catalan, depending upon the native language of the instructor. At different periods in the primary students' tenure at the school, their English language abilities are assessed using the Cambridge exams which are a standardized measure of English proficiency.

Over the last five years the school has employed an innovative approach to teaching

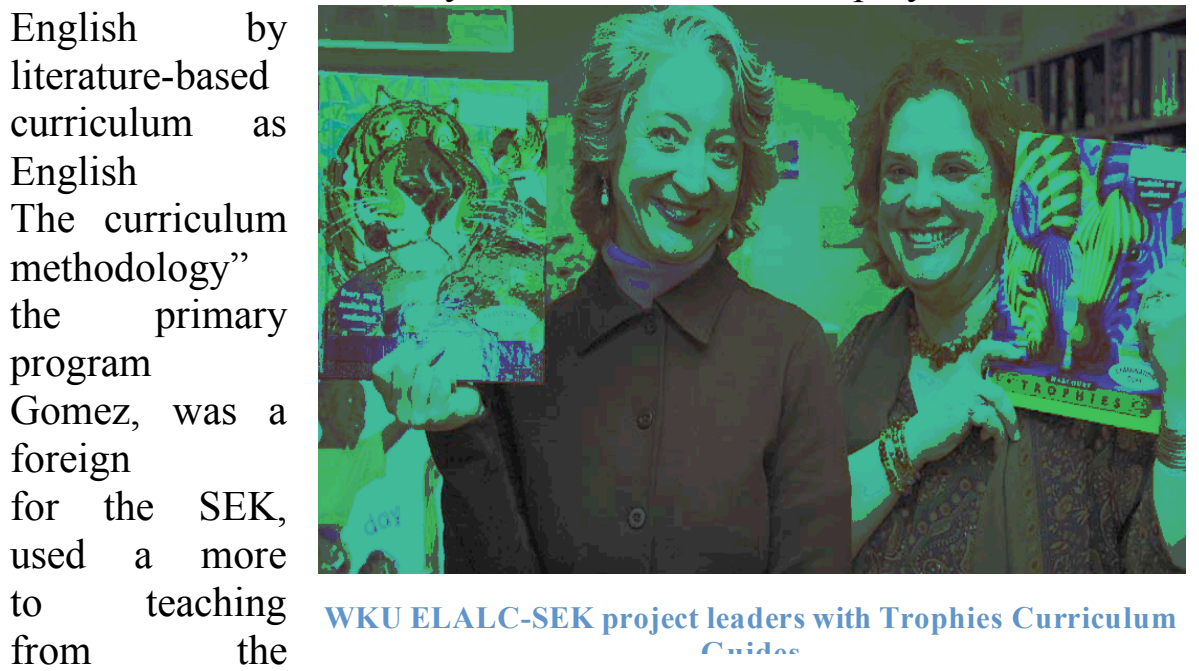
adopting the Trophies literacy their primary grades language program. change or "new as it is described by grades English consultant, Mariela revolutionary idea in language instruction which until then had traditional approach English. However, perspective of content-based language instruction, using what is essentially a literacy curriculum to teach English as a foreign language makes sense, because at the primary level, all children are engaged in language acquisition. By adopting the Trophies curriculum at the SEK, what was once a traditional, approach to English language learning--that of recitation and imitation-was transformed into a more authentic language learning environment, in which students and 
their instructors interact with English through a variety of language arts activities. The driving force behind this curricular change is to improve students' scores on the Cambridge exams. It is the school's hope that a more integrated and motivating approach to language learning will lead to increased scores on these important assessments.

The Trophies curriculum is a reading program developed by Harcourt publishers and is intended for use as an integrated reading curriculum in schools in the United States (http://www.harcourtschool.com/menus/trophies.html). According to the Harcourt web site, Trophies is a research-based, integrated, developmental reading and language arts program. Explicit phonics instruction, direct reading instruction, guided reading strategies, phonemic awareness instruction, systematic, intervention strategies, and assessment comprise the core components of the program. The Trophies program introduces basic literacy skills and concepts using both basal readers and a wide variety of children's literature, all of which are accompanied by supporting lesson plans and prepared instructional materials. Because Trophies incorporates children's literature into all levels of the curriculum, the English language consultant believed that creating a library classroom environment was a natural fit for enhancing and enriching the themes and stories included in the program. Research done by Krashen (2004) and others backs up this idea, as their work has shown that language learning increases when students have access to a rich variety of materials, such as what a school library typically holds, and engage in all areas of literacy learning, including reading, writing, listening, and speaking. For this reason, we were called upon to create a proposal and a plan for implementing library classrooms for the SEK primary program.

\section{School Libraries in Spain and Catalunya}

In the first year of the ELALC-SEK project we studied the Trophies curriculum the school adopted for their English program and conducted an extensive literature review on the status of school libraries in Spain. According to surveys done across the country, school libraries in Spain generally have inadequate collections, circulation management, and are not regularly staffed by trained library professionals (Merlo Vega, 2006). This research indicates that overall there are few school librarians working in Spanish schools, and the function of school libraries as a resource center supporting the school curriculum is not well understood by Spanish education professionals (Gomez Hernandez and Pasadas Urena, 2003). A recent study conducted reports that 80 percent of Spanish schools contain libraries but many do not house collections that meet current IFLA standards (Camacho, 2004). These libraries for the most part are not staffed by specialized professionals and open only when a teacher is available. When someone is appointed to maintain the library, a majority devote only one to five hours per week to library responsibilities.

We confirmed these findings in our own observations in Spanish schools and in interviews with Spanish librarians and teachers. As we visited schools in Catalunya, we documented the wide variety of school libraries we found. In the Garbi school, located outside Barcelona, there existed a fully functional school library and library program staffed by a part time reading teacher. In a small rural school located in the Pyrenees town of St. Julia, the school library occupied a large corner of one of the classrooms. The collection contained both fiction and non-fiction sections and was maintained by one of the classroom teachers as part of her extra duties. At the SEK Catalunya, there were two libraries, one for the primary grades and one for the secondary grades. These libraries contained mostly references books and teaching resources for faculty. Their organization was by subject and did not appear to be staffed or maintained regularly by anyone in the school. 


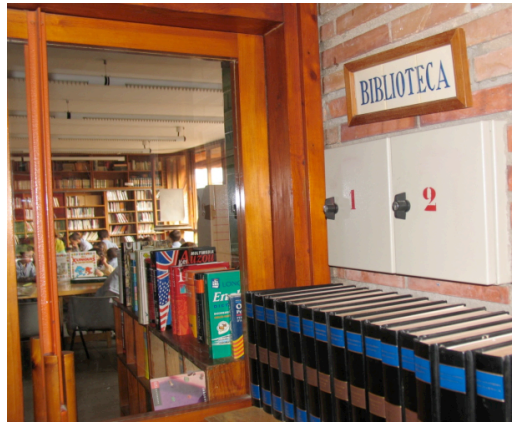

Garbi school library

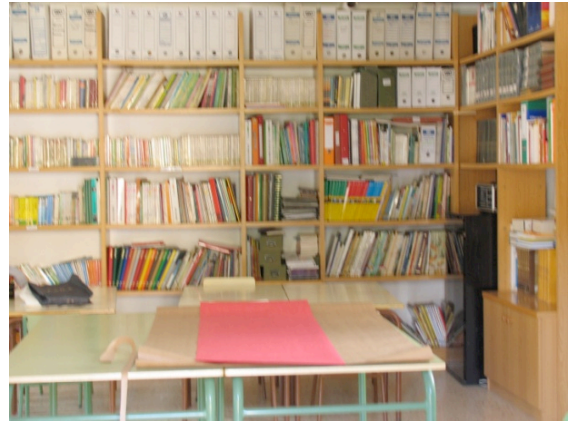

St. Julia school library

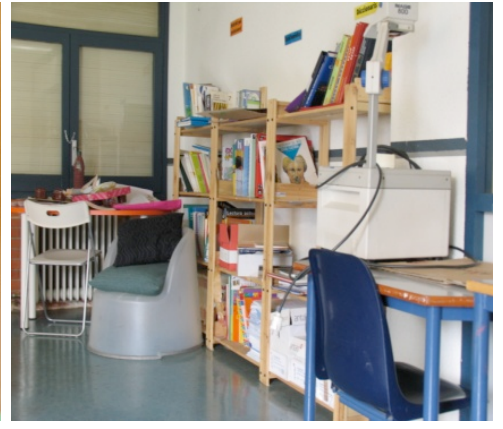

SEK primary grades library

When we interviewed teachers at the SEK-Catalunya about why there didn't appear to be a strong presence of school libraries in Spain, it was a difficult question for them to answer. Although they asserted that their schools had libraries, they admitted that the libraries were not well organized or staffed by trained school librarians. The teachers tried to explain that school libraries as we know them in the United States are not widely found in Spain. As one teacher said, "It just doesn't exist in the culture." The teachers stated that as students they would use the public library to find books and resources they needed for school projects. According to one teacher, "there are resources outside the school (in public and academic libraries), but not inside the school; and these are not directly related to the educational program" (cited in Houston and Spencer, 2007). As we interviewed local public librarians regarding how they interacted with the local schools, they did confirm that students generally came to the library for pleasure reading and to use the Internet, but also came for assistance with research on school projects. The public librarians stated that they often hosted school groups for orientation sessions for students to help with research projects.

\section{Developing the ELALC-SEK concept and proposal}

In the first year of the ELALC-SEK project--armed with background information on the SEK Catalunya, a general understanding of the "new methodology" for English instruction, and a broad understanding of the role of school libraries in Spain--we began the process of developing the concept and proposal for our English Language Library Classrooms.

All of us in the library media education field know that a school library which contains a rich collection of literature in a variety of formats is critical to a school curriculum, specifically one that is based on inquiry and nurturing the interests of learners. As the curriculum of the SEK Catalunya is purportedly based on this approach to learning, the fact that there was no school media center providing resources for students and teachers was a puzzle for us. There seemed to be something missing at the school. Quite recently, the school had implemented the "aula inteligente" or the "smart classroom" concept, which provided computer information resources for students in both the primary and secondary levels. However, there was no accompanying instruction in how to use information technology to access, locate, evaluate and use the information the students found. We knew that the school needed to implement a school library program, but without resources for a central library media center or a professional school media specialist, this concept could never be fully realized. Based on our assessment of the climate, resources, and conditions at the school we decided to introduce the school library concept in our proposal. We therefore proposed the ELALC as a hybrid "library classroom" for each primary grade. The intent of the ELALCs would be to enhance the literature component of the Trophies curriculum by providing a 
library environment rich in English language materials for students to browse, take home, and explore with their families. In the ELALC classroom students would engage in a variety of literature-based activities in English, such as read-aloud, dramatic arts, and independent research projects making use of the library resources. In this way we hoped that the concept of a school library would be introduced in an acceptable way and perhaps the idea would expand and spread to other areas and other languages in the school.

At the end of our initial visit to the SEK we developed our ELALC proposal (http://edtech.wku.edu/ chouston/spain/elalc.doc). In the proposal we formally defined the ELALCs as a hybrid between a classroom and a traditional library. We defined them as centers for English language arts activities within a classroom library setting that used a traditional library classification arrangement and circulation system. Each ELALC would contain an area for books and audiovisual media, an area for seated activities, and an area for large group storytelling or dramatic activities. Our idea was for teachers to use each of these areas of the library classroom to engage their students with activities in English as they moved through the Trophies curriculum. Then, as the collections in the ELALCs grew, students would be able to select books to take home and read with their parents.

As we developed our proposal we were keenly aware that we were working with existing concepts of how school libraries functioned in Spanish schools. We also knew this concept had to change if the ELALCs were going to be successful. Teachers would need to understand that the books and audiovisual media on the ELALC shelves would play a critical role in the curriculum and would be used in very specific ways by students and teachers to supplement and enhance their English language program. Additionally, students would be introduced to basic information literacy concepts such as the difference between fiction and non-fiction and how a library is organized for finding information. $\backslash$

To gain support for the idea we began discussing the concept with some of the primary English teachers. They expressed enthusiasm for the idea, because they saw that the expanded English language resources from the ELALCs would encourage students and parents to interact with the language in more ways and for longer periods of time. The teachers saw many advantages to having the students take books home to read independently and with their parents. They also saw the classroom library as an environment that supported the Trophies curriculum which relied heavily on integrated language arts activities such as storytelling, reading, and writing. However, one concept that the teachers initially did not understand was how the ELALCs had the potential to do more than promote reading and English language appreciation. They could also be an environment for teaching information literacy skills and promoting lifelong learning.

\section{ELALC-SEK Project Implementation and Orientation}

The proposal for the ELALCs was received warmly by the school administrators at the SEK, as improving the English language skills of the students is a high priority for the primary program. However, because school libraries in Spain are rare, and trained school librarians even more rare, the school administration recognized the need for additional teacher training and realized that this must be done in a context where school libraries are an integrated part of the school curriculum. After the proposal was formally approved, a major part of implementing the ELALC-SEK project involved providing technical support and training for teachers at the SEK. For in order to be able to manage a substantial collection of literature and audiovisual media, teachers at the SEK would need to know how to apply basic principles of library organization, administration, collection development, and programming. To support implementation of the program, the school administrators agreed to send two English teachers to the WKU campus in Bowling Green for additional training in school 
librarianship. In successive years, two, then six, and then six more teachers from the SEK came to Bowling Green for workshops. In addition to providing library administration and collection development assistance, we saw this visit as an opportunity to expand the SEK teachers' concept of the school library to one that embraced a more integrated approach to resource-based education. As part of their training, the teachers from the SEK toured school libraries and visited with school librarians; they also participated in workshops on collection development, information literacy, library management, and poured through children's fiction and non-fiction titles at the local bookstores and the public library. The training lasted two weeks. During this time the teachers developed an extensive bibliography of print and media titles for purchase by the SEK, collected library lesson plans, and created presentations and reports for the SEK administration on the work they completed at WKU.

Over the years we have been providing professional development opportunities for the SEK teachers it has been very interesting for us to observe the changes in how they perceive the role of the ELALCs in their English curriculum. In initial interviews with teachers their interests in the ELALCs were focused on creating a more enriched learning environment to support the "new methodology" of the Trophies curriculum. They stated that their goals were to improve students' grasp of English by having access to more reading materials at their developmental level. As one teacher put it, "We want to submerge the kids

in the English

library corner was a will create a whole English and be a place for them to (cited in Houston, expectations were enriched audio, and the students would English and improve comprehension.

Typically at visits, the primary had in mind was to English titles as a bibliography of

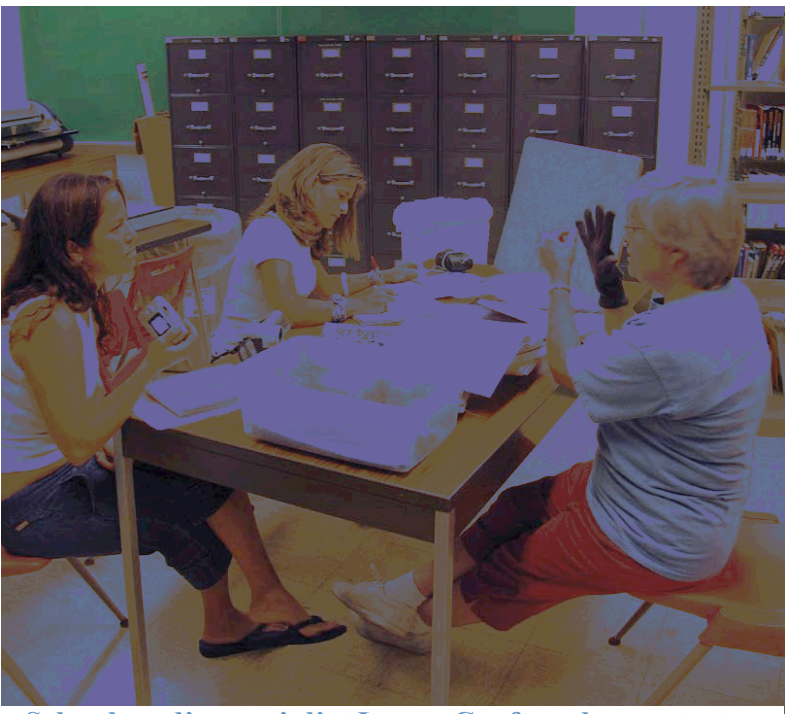

School media specialist Laura Crafton demonstrates language arts activity to SEK teachers in Bowling Green language. Before, the box of books, but this environment for more comfortable learn and grow" 2007). Their that with a more environment of print, audiovisual media, read and hear more their vocabulary and

the beginning of their goal the SEK teachers examine as many possible and develop English language 
resources for their classrooms. However, by the end of the two week training teachers demonstrated a more complete understanding of the role a school library plays as an integrated part of the curriculum. In addition to understanding the importance of a school library in promoting reading, the teachers also began to understand the critical role played by school libraries in promoting information literacy and lifelong learning. According to one teacher:

We will teach them how a library works, how to treat books, and how to look for information wisely; this means thinking first what to look for, when and how to use that information, to later analyze it and synthesize it into their conclusions. From my point of view ELALC is an innovation in our school environment as we are merging the American library concept inside a classroom in order to support and enhance the English curriculum taught in our school. It is important to keep in mind that this is not the way we use the school library in the traditional Spanish system. (cited in Houston, 2006)

According to another teacher, the training at WKU not only expanded her concept of the school library but also provided materials and guidance for creating a library program within her own classroom:

During our stay at WKU I got to both study the theoretical side of collection management and also see and experience how librarians did it themselves. We also got a lot of information on how to approach and teach Information Literacy, from books and classes, but also from worksheets librarians used, or some we created ourselves. In sum, this has been a great immersion in the media specialist world and a really good training for this incredible task we are about to start. I am going back home with clearer ideas of what needs to be done (cited in Houston, 2007).

At the end of their visit we introduce the SEK teachers to the idea of the library media specialist as instructional leader, and let them know that as school innovators, they are also in a leadership position. Although this idea did make them feel uncomfortable at first, both teachers shared a vision for incorporating the ELALC concept in all the primary grades and were equipped with the knowledge, skills, and motivation to facilitate this change. As two teacher state:

Our goals are teaching Information Literacy, helping them to become lifelong learners as well as independent readers in another language. We must keep our goals in perspective. I am teaching second graders and I can ask from them to an extent. They will learn a lot from me but only if this goes on it will have an impact on their education. This means consistency, working on this new approach, and with time they will achieve it. To succeed this project needs to go on to higher grades or our effort will be completely pointless (cited in Houston, 2007).

The ELALC being an English collection amplifies the kids' learning in a lot of ways. I think I will present this to the parents as the perfect corner 
for a different type of educational activity, where reading, having fun and learning will all mix up in one. They will use the ELALC as their favorite storytelling corner, as their research base when a project is going on, as a way of looking for books and reading for pleasure and also to be mature enough to pick books, take them home and complete reports about them. Engaging the families with the books that can be taken home is also a novelty and I think it will be very well received from the parents (cited in Houston, 2007).

\section{Programming and Collection Building for the ELALC-SEK project}

Every new year at the SEK also begins the implementation of a new ELALC at a different grade level. Teaching resources, such as new literature titles, audio books, puppets, and lesson plans brought from Bowling Green to Spain are among the first items to become part of the new ELALCs. As the fiction and non-fiction titles the teachers selected during their visit to Bowling Green arrive, the new shelves housing the emergent ELALCs begin to fill. As the ELALCs become a physical presence in the teachers' classrooms, the different

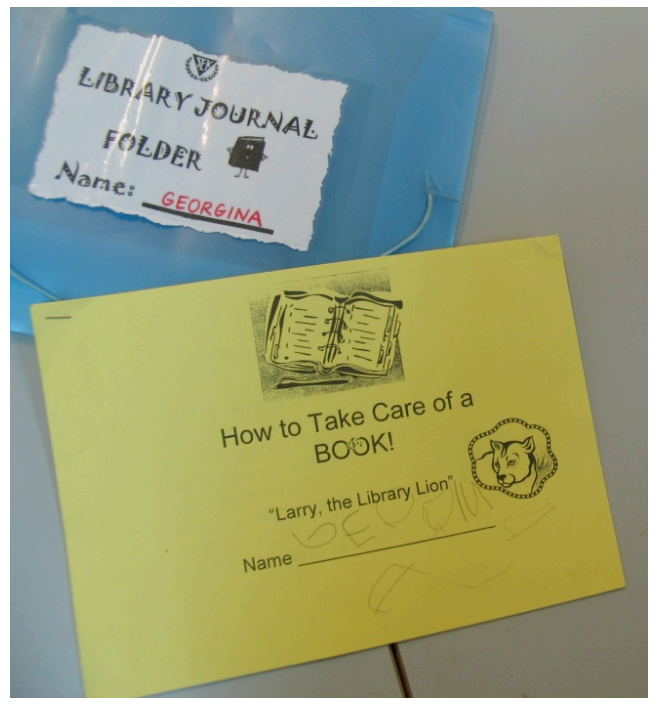

ELALC programming includes a library journal and book care activity ways in which these resources are used also begin to emerge and become a regular part of classroom activity. At all levels of the primary program, the English teachers now use the ELALCs as part of a designated "library time." During this time, students hear story English, either read aloud or on audio tape. They also learn about the parts of a book and how to care for a library book. Then there is "check out" time where students are able to select a book for themselves. As each

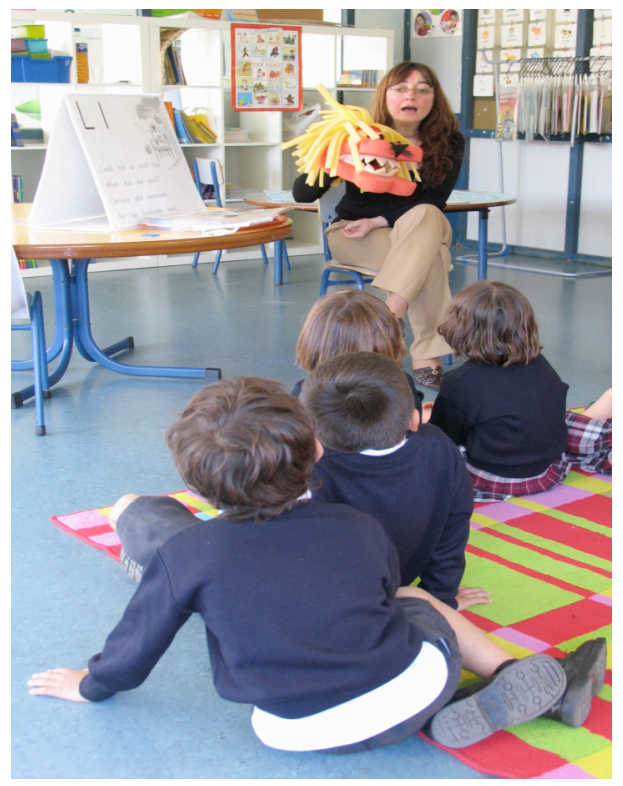
year progresses, consultants from WKU visit the SEK and provide continuing professional development for the ELALC project. One year, a library media specialist from the Bowling Green area demonstrated ways to engage students with literature through language arts activities such as puppetry and dramatic play. In another year, a teacher in English as a Second Language introduced activities on developing oral fluency through activities involving role-play, drama and movement.

On one hand it has been exhilarating to see how our original proposal has developed into a full-fledged educational program used with students. It is wonderful to see the books arranged by classification and to see students using shelf markers and book cards to select books for themselves. However, on the other hand, it has been a bit disappointing to see how the ELALCs have become separate from the regular classroom. Currently, the ELALCs are 
used during a special "library time" as opposed to being a fully integrated part of the curriculum. I suppose we should have predicted this, as this type of marginalization often happens in elementary schools in the United States even when there is an active and involved full time media specialist at the school working daily on collaborative activities with teachers. But we can always hope that as the ELALCs grow and begin to be utilized by more and more teachers that they will become a more central component of the curriculum.

\section{ELALC-SEK Reflections and Final Comments}

We are technically in the last year of this project and the project now faces an uncertain future because of funding shortages. We are not sure if next year WKU will be able to support faculty involvement in the program or our international visitors from the SEK. However, we do hope that our work with the SEK-Catalunya has provided the staff at the school with the basic tools in library organization and collection development to continue the project on their own. As for those of us at WKU and all of the practitioners who have been involved with the ELALC-SEK project, the experience has been invaluable. I cannot say enough about how this experience in international collaboration has broadened our own understandings of literacy learning, language acquisition, and the essential role a school library plays in promoting reading, writing, listening, and speaking skills in native and foreign languages.

I believe also that this project has made an indelible impact on the SEK Catalunya. I say this because last year the school hired a full time librarian and created a dedicated space for a comprehensive library that will serve the schools' resource needs in all three languages - Catalan, English and Spanish. This new development is most likely the result of the need to meet requirements for participation in the IB and PYP programs, but I can't help but think our presence also played a role in this decision. How the ELALCs will be integrated into the school's library collection remains to be seen, as moving both the ELALC collections and primary students back and forth from the main library would take up valuable administrative and instructional time.

However, I must admit that every year is a new one at the SEK-Catalunya and with the ELALC-SEK project. For example, as we speak the new librarian from the SEKCatalunya is on the WKU campus engaging in professional development activities with the SEK English teachers and practicing media specialists from Bowling Green area schools. How these experiences will result in future innovations at the SEK is anyone's guess. What we do know is that this experience in international collaboration will continue to influence and expand our ideas about literacy and language learning, and improve our work with children as we help them develop the knowledge and skills they will need to become information literate, lifelong learners in the 21 st century.

\section{References}

Camacho Espnosa, J. A. (2004). La biblioteca escolar en Espana: pasado, presente...y un modelo para el futuro. Madrid: Ediciones de la Torre.

Gomez Hernandez, J., and Pasadas Urena, C. (2003) Information literacy developments and issues in Spain. Library Review, 52 (7), 340-348. 
Houston, C. (2006). Building capacity for global education in school library media education through international exchange. IFLA Journal, 32(3), 209-213.

Houston, C. \& Spencer, R. (2007). From aula biblioteca to biblioteca aula: integrating a school library program into the English language program of a Spanish school. Library Review, 56(1), 34-44.

Krashen, S. (2004). The power of reading, 2nd ed. Portsmouth, NH: Heinemann.

Merlo Vega, Jose Antonio. (2006). School libraries, information literacy and reading promotion initiatives in Spain. International Association of School Librarians Annual Conference,, Lisbon.

\section{Biographical Note}

Dr. Cynthia Houston is an assistant professor in the Library Media Education program at Western Kentucky University. She has been involved in international school library collaboration since 2004. For more information on the ELALC-SEK project visit the project web site at http://edtech.wku.edu/ chouston/spain/elalc.html

\section{Statement of Originality}

This statement certifies that the paper above is based upon original research undertaken by the author and that the paper was conceived and written by the author(s) alone and has not been published elsewhere. All information and ideas from others is referenced. 